\title{
The genetic structure of Escherichia coli populations in primary and secondary habitats
}

\author{
David M. Gordon, ${ }^{1}$ Sonja Bauer ${ }^{1}$ and James R. Johnson ${ }^{2}$
}

\footnotetext{
1 School of Botany and Zoology, Australian National University, Canberra, ACT, Australia

2 Medical Service, VA Medical Center and Department of Medicine, University of Minnesota, Minneapolis, MN, USA
}

Author for correspondence: David M. Gordon. Tel: +61 026125 3552. Fax: +61 0261255573. e-mail: David.Gordon@anu.edu.au

\begin{abstract}
Escherichia coli were recovered from the members of two two-person households and their associated septic tanks. The $E$. coli were isolated using selective and non-selective isolation techniques, characterized using the method of multi-locus enzyme electrophoresis and screened for the presence of virulence factors associated with extra-intestinal disease by using PCR. The growth rate-temperature relationships of strains from the two habitats were also determined. Temporal variation explained $25 \%$ of the observed electrophoretic type (ET) diversity in the humans. Among-host variation accounted for $\mathbf{2 9} \%$ of the observed allelic diversity. In one household, ET diversity of the $E$. coli population in the septic tank was significantly lower than ET diversity in the humans providing the inputs to the septic tank. Molecular analysis of variance revealed that, on average, strains recovered from the septic tank of this household were genetically distinct from strains recovered from the humans providing the faecal inputs to the septic tank. Further, the growth rate-temperature response of strains differed between strains isolated from the septic tank and strains isolated from the humans. Septic tank isolates grew better at low temperatures than strains isolated from humans, but more slowly at high temperatures compared to the human isolates. By contrast, no real differences in ET diversity, allelic diversity, or the growth charcteristics of strains could be detected between strains from the humans and strains from the septic tank of the other household. The results of this study suggest there are strains of $E$. coli that are better 'adapted' to conditions found in the external environment compared to strains isolated from the gastrointestinal habitat. Further, the finding that the numerically dominant clones and clonal diversity in secondary habitats can differ substantially from those found in the source populations will confound efforts to identify the sources of faecal pollution in the environment.
\end{abstract}

Keywords: population structure, coliforms, human, septic tank

\section{INTRODUCTION}

The contamination of soil and water by faeces is considered a human health risk (Leclerc et al., 2001). Consequently, there has always been a great deal of concern regarding the level of coliform bacteria counts in the environment. In many parts of the world, coliform counts are considered to be above acceptable levels (Dombeck et al., 2000). Faecal contamination by humans, domestic animals and wildlife, as well as runoff from agricultural land, inadequate septic systems and

Abbreviations: AMOVA, molecular analysis of variance; ET, electrophoretic type; MLEE, multi-locus enzyme electrophoresis. sewage overflow are though to be the sources of coliform bacteria (Leclerc et al., 2001). In an effort to manage the problem of elevated coliform counts, programmes are under way in many parts of the world to develop methods that will allow the source of the faecal contamination to be determined (Parveen et al., 1999; Dombeck et al., 2000). For example, can elevated coliform counts be attributed to human or animalderived faecal contamination, or can the geographical source of the contamination be identified? Much of this work focuses on Escherichia coli, as it is the dominant member of the aerobic flora of most humans and the cause of a significant fraction of human bacterial disease (Siitonen, 1994; Leclerc et al., 2001). 
Savageau (1983) observed that the life cycle of enteric bacteria such as E. coli involves a transition between two distinct environments. He considered the primary habitat of E. coli to be the gastrointestinal tract of mammals, whilst soil, water and sediment represents the species' secondary habitat. These two habitats differ considerably in the biotic and abiotic conditions and resources they present to E. coli. Gordon (2001) argues that the success of any effort to trace the sources of coliform contamination depends on several assumptions being valid. One of the most significant of these assumptions relates to what happens to the clonal composition of E. coli populations during the transition between the species' primary and secondary habitats. For the source of coliform contamination to be determined it must be assumed that the clonal composition of E. coli isolated from soil and water represents the clonal composition of E. coli in the host population responsible for the faecal inputs to the environment (Gordon, 2001).

Two hypotheses have been proposed to describe the manner in which E. coli responds to the transition from its primary to secondary habitats. Savageau (1983) suggested that E. coli cells cope with the transition by possessing a dual regulation system, where genes with products in high demand are under positive control, whilst genes with products in low demand are under negative control; the controls systems alternate depending on the specific demands imposed by the primary and secondary environments. Savageau (1983) presented numerous examples of physiological functions in enteric bacteria that are consistent with the demand theory and it has been demonstrated that, in E. coli, some genes appear to be preferentially expressed in the external environment (Espinosa-Urgel \& Kolter, 1998).

If $E$. coli possesses a dual regulation, this would lead to the prediction that the clonal composition of E. coli in host populations does reflect that in the external environment. If selection were the dominant force determining the outcome of the transition, then the assumption underlying efforts to trace the source of coliform contamination would be invalid.

Few studies have examined the genetic structure of $E$. coli from the secondary habitat (Pupo \& Richardson, 1995; Parveen et al., 1997, 1999). Due to the difficulties associated with unambiguously identifying the source of E. coli found in the environment, there has been only one published study that has examined the genetic structure of E. coli isolated from hosts and the environment where the faeces of these hosts accumulated (Whittam, 1989). Whittam (1989) suggested that selection is the dominant force acting on E. coli during the transition from the primary to secondary habitats. That is, there are strains of E. coli primarily adapted to the host environment, whilst other strains are better adapted to the external environment. Whittam (1989) based this conclusion on the results of a study of E. coli isolated from domestic birds and the litter on which these birds were raised. Over 500 isolates were collected from the two habitats and 113 distinct strains were identified. Only $10 \%$ of the strains were recovered from both birds and the secondary environment. The data revealed the existence of two genetically distinct groups of strains. The majority of the strains isolated from the birds were representatives of one cluster while the majority of strains isolated from the secondary environment were representatives of the other cluster.

The purpose of the present study was to examine the genetic structure of E. coli populations in the primary and secondary habitats where the faecal inputs to the secondary environment were unambiguous. To this end, E. coli were isolated from two two-person households and their associated septic tanks. E. coli were isolated using selective and non-selective techniques, characterized using the method of multi-locus enzyme electrophoresis (MLEE) and further characterized by PCRbased screening for the presence of 30 virulence factors associated with extra-intestinal disease. The thermal conditions of a septic tank and a human are very different and Okada \& Gordon (2001) have demonstrated that natural isolates of E. coli differ substantially in their growth response to different temperatures. Accordingly, the growth rate-temperature relationships of strains from the primary and secondary habitats were also characterized in order to determine if these relationships differed among strains isolated from these two environments.

\section{METHODS}

The study populations. E. coli populations were sampled from each individual in two two-person households and from their associated septic tanks. The households were located in New South Wales, near Canberra, ACT, Australia and were within $15 \mathrm{~km}$ of each other. Each household consisted of one male and one female couple aged between 40 and 50 years. The members of the households did not interact socially; however, the male members of each household shared a common workplace. No person had taken antibiotics for at least one year prior to sampling.

For a minimum of 3 months prior to sampling, the only faecal inputs to either septic tank were from their respective household members. The septic tanks are simple holding tanks with a single inlet and outlet. The tank of household 1 was cylindrical in shape, whilst that of household 2 was rectangular, but both had working volumes of about $900 \mathrm{l}$. The sole input to the septic tank of household 1 was a toilet that was flushed using tank-stored river water. In household 2, the inputs were from a toilet and a kitchen sink and the water source was tank-stored rainwater. Flow rates into the septic tanks ranged from 10 to $20 \mathrm{l} \mathrm{day}^{-1}$. The temperature of the septic tanks was about $25^{\circ} \mathrm{C}$ when sampling occurred.

Faecal sample collection and bacterial isolation. In household 1 the samples were collected in the following sequence: people, 4-day interval, septic tank, 3-day interval, people, 4-day interval, septic tank. In household 2 the sequence was: people, 4-day interval, septic tank, 7-day interval, people, septic tank. A $10 \mathrm{~g}$ subsample of the faeces produced by each person was suspended in sterile $0.85 \%$ saline to a total volume of $100 \mathrm{ml}$. The contents of the septic tanks were stirred for 5 min with a large 'paddle' prior to the collection of a 11 
sample. The samples were agitated for $30 \mathrm{~min}$ to dislodge the bacteria from the solids, briefly allowed to settle, and then serially diluted in 10-fold steps using sterile $0.85 \%$ saline. From each of the dilutions, $100 \mu \mathrm{l}$ aliquots were plated onto two MacConkey agar plates (Power \& McCuen, 1988), which were then incubated overnight at $37^{\circ} \mathrm{C}$.

For each sample, up to 100 colonies were chosen at random from the MacConkey agar plate resulting in 50-300 colonies per plate. The colonies were transferred onto another MacConkey plate for temporary storage. These isolates were denoted as the dominant isolates, as they were the most abundant clones present in the sample. This procedure allowed the detection of strains that were present at a frequency as low as $5 \%$ of the total E. coli cell population in the sample with $90 \%$ certainty.

To recover strains occurring at frequencies of less than $5 \%$, a selective plating procedure was used. From each of the serial dilutions of every sample, $100 \mu \mathrm{l}$ aliquots were plated onto three sets of selective plates. The first set was minimal-media agar plates (Power \& McCuen, 1988) containing 0.04\% (w/v) of one of the following sugars: adonitol, dulcitol, inositol, putrecine, raffinose, rhamnose, salicin, sorbose, sucrose, or trehalose. The second set was MacConkey agar plates containing one of the following antibiotics: $100 \mathrm{mg}$ ampicillin $\mathrm{l}^{-1}, 25 \mathrm{mg}$ chloramphenicol $\mathrm{l}^{-1}, 100 \mathrm{mg}$ erythromycin $\mathrm{l}^{-1}$, $50 \mathrm{mg}$ gentamicin $\mathrm{l}^{-1}, 50 \mathrm{mg}$ kanamycin $\mathrm{l}^{-1}, 50 \mathrm{mg}$ neomycin $\mathrm{l}^{-1}, 100000 \mathrm{U}$ penicillin $\mathrm{l}^{-1}, 20 \mathrm{mg}$ spectinomycin $\mathrm{l}^{-1}, 100 \mathrm{mg}$ streptomycin $\mathrm{l}^{-1}$ or $20 \mathrm{mg}$ tetracycline $\mathrm{l}^{-1}$. The third set of plates was used to isolate cells capable of growing: at an elevated temperature $\left(44.5{ }^{\circ} \mathrm{C}\right.$, MacConkey agar); or under acidic [HCl, pH 4, LB agar (Power \& McCuen, 1988)]; basic ( $\mathrm{NaOH}, \mathrm{pH} 10, \mathrm{LB}$ agar) or high salinity $(\mathrm{NaCl}, 2 \%, \mathrm{LB}$ agar) conditions. All selective plates were incubated at $37^{\circ} \mathrm{C}$ with the exception of the $44.5{ }^{\circ} \mathrm{C}$ plates. A single colony was chosen from each selective plate, provided that the dilution factor for that plate indicated a cell density at least 100 -fold lower than the total cell density in the sample.

The selective plating methods used in this study enabled uncommon strains to be isolated; however, not all of the rare strains present would be detected. The strains recovered from the people through selective plating at densities of less than $10^{5}$ cells $\mathrm{g}^{-1}$ were designated minority isolates. Strains recovered from the septic tank through selective plating were not specifically designated as minority strains. E. coli cell densities in human faeces were about $10^{7}$ cells $\mathrm{g}^{-1}$, whilst cell densities in the septic tanks were about $10^{4}$ cells $\mathrm{ml}^{-1}$. Selective plating recovered no strains from the septic tanks that occurred at a density of less than $10^{2}$ cells $\mathrm{ml}^{-1}$.

All isolates were identified as E. coli using specific biochemical characteristics : growth on minimal lactose agar plates, lack of growth on minimal citrate agar plates, and indole production. For a subset of 150 isolates, identifications were confirmed using the BBL Crystal Enteric/Nonfermenter kits in conjunction with the BBL Crystal System Electronic codebook (Becton Dickinson). In every instance the original identification was confirmed.

Genetic characterization of isolates. Protein extracts were prepared as described by Gordon \& Lee (1999). The samples were characterized using MLEE. The MLEE assays were carried out as described by Gordon \& Lee (1999) for the following enzyme systems: ADH (alcohol dehydrogenase), $\mathrm{MDH}$ (malate dehydrogenase), PGD (6-phosphogluconate dehydrogenase), PGI (phosphoglucose isomerase), PGM (phosphoglucomutase), AK (adenylate kinase), G6PD (glu- cose-6-phosphate dehydrogenase), IDH (isocitrate dehydrogenase), ME (malic enzyme), MPI (mannose-6-phosphate isomerase), $\mathrm{MR}$ (menadione reductase), $\mathrm{SDH}$ (shikimic acid dehydrogenase), and SOD (superoxide dismutase).

One strain representing each of the different MLEE profiles (electrophoretic types, ETs) observed in each of the populations was further characterized for the presence or absence of 31 genes implicated as virulence factors associated with extraintestinal disease using a multiplex PCR-based assay as described by Johnson \& Stell (2000) and Johnson et al. (2001a).

Growth characteristics. The growth characteristics of one strain representative of every ET from each of the six populations were determined. Cells were grown overnight at $37^{\circ} \mathrm{C}$ in the wells of a microtitre plate. The overnight cultures were diluted using $0.85 \%$ saline and each well of a microtitre plate containing $250 \mu \mathrm{LB}$ broth was inoculated with about $10^{3}$ cells of a strain. The optical denisty of the culture was monitored at regular intervals $\left(640 \mathrm{~nm}, E_{\max }\right.$, Precision microplate reader, Molecular Devices) until the cultures had achieved stationary phase. Maximal growth rate was determined at 12, 14, 17.5, 19, 25, 26.5, 29, 32, 34, 37, 39, 41 and $44{ }^{\circ} \mathrm{C}$. Maximal growth rate at a temperature was defined as the largest value observed for $\ln \left(\mathrm{OD}_{t+1} / \mathrm{OD}_{t}\right) / \Delta t$, where $t$ is the time in hours from the start of the experiment.

Statistical analyses. Isolates with the same MLEE profile were designated as representatives of an electrophoretic type (ET). ET diversity $(G)$, allelic diversity of a locus $(h)$ and mean allelic diversity $(H)$ were calculated as described by Gordon $\&$ Lee (1999). Estimates of allelic diversity were based on the unique ETs and the frequency with which the ETs occurred was not considered.

Molecular analysis of variance (AMOVA) (Excoffier et al., 1992) was used to determine how much of the observed MLEE variation could be explained by a population level effect. AMOVA is built on the principles of classic analysis of variance. However, the data analysed with Amova are the matrix of pairwise genetic distances. The estimated variance components are expressed as the proportion of the total variance explained by the population level effect. The variance statistics have an interpretation equivalent to the classic single-locus $F$ statistics of Wright (1943) and the multi-locus $G$ statistics of Nei (1978), which are used for assessing the extent of population differentiation. The AmOVA analysis was done using the software Winamova 1.5 (Excoffier et al., 1993).

Two approaches were used in analysing the data. In the first approach, only the dominant ETs (those recovered through non-selective plating) were considered together with their frequency. This analysis examined the extent to which ET diversity varied among populations, that is how the relative abundance of the different ETs differs among populations. In this analysis, ETs are considered as the same or different. The second approach considered only the ETs, dominant and minority, present in each population but not their frequency. This approach did incorporate a measure of how genetically dissimilar the ETs were from one another. The measure of genetic distance used was the number of MLEE loci at which two ETs had different alleles. Therefore, this analysis considered the extent to which allelic diversity varied among populations.

The genetic similarity among the ETs recovered was graphically illustrated using cluster analysis (UPGMA). The distance between pairs of ETs was quantified as $-\ln (1-p)$, where $p$ is the portion of loci at which two strains differ. The distance measure was based on the MLEE and virulence profiles of the 
ETs. Principal co-ordinates analysis (PCO) was used to reduce the dimensions of the distance matrix. Scores from the first four PCO axes were incorporated in analyses of variance that examined the extent to which the growth characteristics of the strains varied among populations.

\section{RESULTS}

\section{Among-habitat variation}

Household 1. Variation between the two samples from the septic tank accounted for $13 \%$ (AMOVA : $p<0.001$ ) of the observed dominant ET diversity in the septic tank. There were 18 ETs recovered from the two individuals providing the inputs to the septic tank (Table 1) and six of these (ETs 22, 39, 46, 52, 69, 73) were present in the septic tank (Fig. 1). The most abundant ET (52) in the septic tank was also the most abundant ET in the male of this household. Pooling isolates from the two individuals of household 1 (primary habitat) resulted in an estimated ET diversity of 0.60 (Table 1 ). ET diversity in this household's septic tank was 0.76 (Table 1 ). Contrasting ET diversity in the primary and secondary habitats explained 4\% (AMOVA: $p<0.001$ ) of the observed ET diversity in household 1. The significant AMOVA result indicates that there was a small but significant increase in the ET diversity in the septic tank as compared to the primary habitat.

The allelic diversity of ETs from the primary habitat was virtually identical to the allelic diversity of ETs in the septic tank (Table 1). Whilst 22 ETs were only recovered from the septic tank, a comparison of the ETs from the primary and secondary habitats explained $0 \%$ (AMOVA: $p>0.79$ ) of the observed allelic diversity in household 1. Thus, the ETs recovered from the septic tank did not represent a population of strains genetically distinct from the ETs occurring in the primary habitat.

Household 2. Variation between sample dates explained 0\% (AMOVA: $p>0 \cdot 15$ ) of the observed dominant ET diversity in the septic tank. Twenty-five ETs were recovered from the members of household 2 (Table 1 ) and three of these (ETs 15, 16, 17) were also isolated from this household's septic tank (Fig. 2). Combining isolates from the two hosts resulted in an ET diversity estimate of 0.77 (Table 1). The diversity of ETs in the septic tank was substantially lower, 0·14 (Table 1). Contrasting ET diversity in the primary and secondary habitats of this household explained $48 \%$ (AMOVA: $p<0.001)$ of the observed ET diversity.

The allelic diversity of ETs from the primary habitat was lower than the allelic diversity observed in isolates from the septic tank (Table 1). A comparison of allelic diversity in primary versus secondary habitats explained $8 \%$ (AMOVA : $p<0.004$ ) of the allelic diversity in household 2. Thus, the E. coli recovered from the septic tank were, on average, genetically distinct from the E. coli recovered from the people in this household.

The most abundant ET (17) in the septic tank represented 153 out of 162 isolates examined from this population. The same ET was also recovered twice from the male of this household (Fig. 2). However, the strains from the male and the septic tank had very different virulence factor profiles and the septic tank strain is unlikely to be derived from the strain observed in the male. The strain from the male was positive for 15 virulence factors, most of which are thought to be encoded on the chromosome (Johnson, 1991; Johnson \& Stell, 2000). The strain from the septic tank shared only four of the factors found in the strain from the male and had three additional factors (iroN, iss and $c v a C$ ) that can be plasmid determined (Johnson, 1991; Johnson \& Stell, 2000). These three plasmid-determined factors were absent from any ET isolated from the people in this household.

\section{Within-host variation}

Non-selective plating of the faecal samples resulted in 3-9 dominant ETs being recovered per person (Table 1). Dominant ET diversity in a person varied from 0.05 to 0.57 (Table 1). Overall, variation between sample dates accounted for $25 \%$ (AMOVA: $p<0.001$ ) of the ET diversity. However, the extent to which temporal

Table 1. Sample size and MLEE-based diversity estimates for E. coli populations from human couples (male and female) living in two households and their associated septic tanks

See Methods for the definitions of terms.

\begin{tabular}{|llccccc|}
\hline Household & Population & No. isolates & $\begin{array}{c}\text { No. dominant } \\
\text { ETs }\end{array}$ & $\begin{array}{c}\text { No. minority } \\
\text { ETs }\end{array}$ & $\begin{array}{c}\text { Dominant ET } \\
\text { diversity }\end{array}$ & $\begin{array}{c}\text { Mean allelic } \\
\text { diversity }\end{array}$ \\
\hline 1 & & 200 & 3 & 6 & $0 \cdot 05$ & $0 \cdot 17$ \\
& Male & 192 & 6 & 3 & $0 \cdot 33$ & $0 \cdot 60$ \\
& Female & 392 & 9 & 9 & $0 \cdot 76$ & $0 \cdot 50$ \\
2 & Primary habitat & 200 & 24 & 4 & $0 \cdot 57$ & $0 \cdot 24$ \\
& Septic tank & 173 & 9 & 4 & $0 \cdot 77$ & $0 \cdot 14$ \\
& Male & 176 & 9 & 6 & $0 \cdot 14$ \\
\end{tabular}




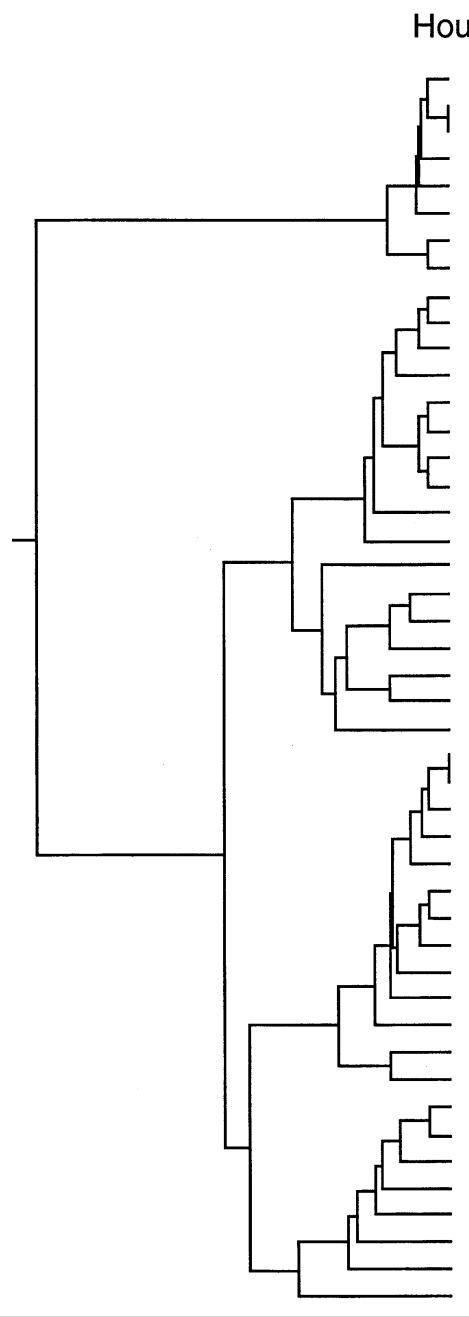

Household One

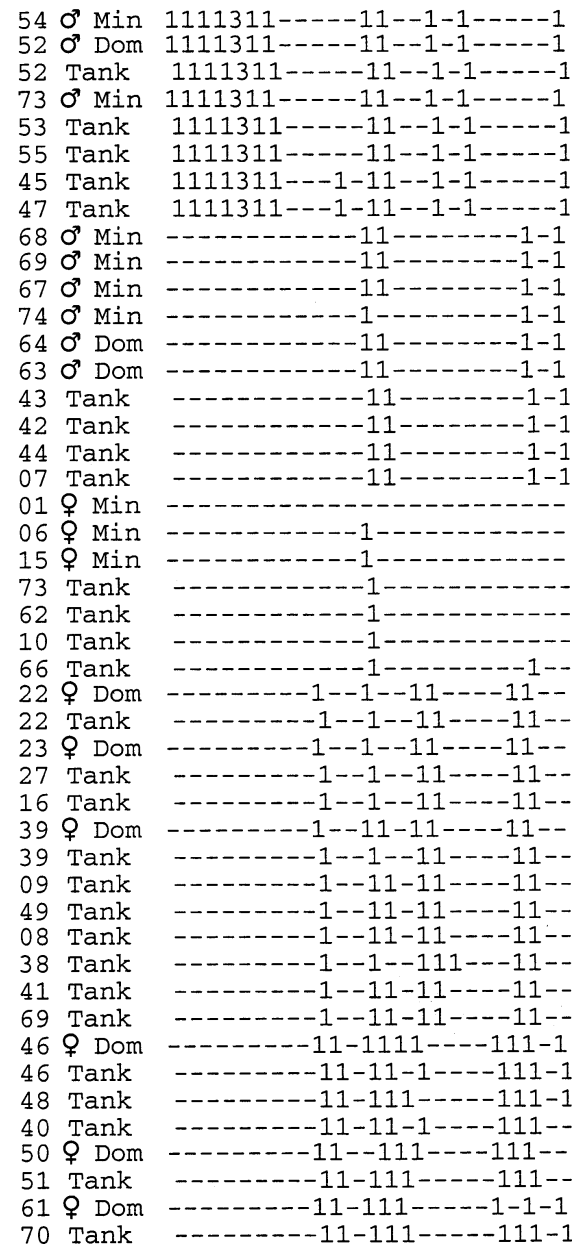

Fig. 1. Genetic similarity among E. coli strains isolated from the human members and septic tank of household 1 . The distance matrix used in the cluster analysis (UPGMA) was based on the MLEE results for 16 loci and the presence or absence of 30 virulence factors associated with extra-intestinal disease. The numbers to the right of the phenogram represent the ET designation. Min, minority strains occurring at low frequencies that were recovered through selective plating; Dom, numerically dominant strains recovered through non-selective plating. Tank denotes strains isolated from the septic tank. The numbers and dashes denote the presence (1) or absence (-) of a particular virulence factor and which allele of papG was present. From left to right the virulence factors are: $p a p A, p a p C, p a p E F$, papG, allele of papG, sfalfoc, sfaS, afaldra, bmaE, ure, ompT, iha, fimH, kpsMT II, kpsMT K1, fyuA, iroN, iutA, hlyA, cdtB, ibe $A$, iss, traT, cvaC, malX. All ETs were negative for focG, kpsMT III, rfc, cnf1. variation explained the observed ET diversity varied considerably among the four humans. Temporal variation accounted for $0 \%$ (AMOVA: $p>0.3$ ) of the observed ET diversity for the male of household 1, 26\% (AMOVA: $p<0.001$ ) of the observed diversity for the female of household 1, 14\% (AMOVA: $p<0.001$ ) for the male of household 2 and $85 \%$ (AMOVA: $p<0.001$ ) for the female of household 2. The large temporal effect for the female of household 2 was caused by a different ET being numerically dominant in each of the samples, although both ETs were recovered on each sampling occasion.

Selective plating resulted in an additional 3-6 ETs being recovered per person (Table 1). Most of the minority ETs occurred at a frequency of about $10^{3}$ cells (g faeces $)^{-1}$. Virtually all types of selective plates resulted in the recovery of one or more of the minority strains. A comparison of dominant and minority ETs, nested within-hosts, revealed that partitioning the ETs on this basis accounted for $15 \%$ (AMOVA: $p<0.001$ ) of the observed allelic diversity. However, comparisons of dominant and minority strains at the individual host level showed this result was due to differences between dominant and minority ETs in the two female hosts.
The dominant/minority contrast explained $26 \%$ (amova: $p<0.04$ ) of the allelic diversity for the female of household 1 and $22 \%$ (AMOVA : $p<0.03$ ) for the other female. This contrast explained none of the observed allelic diversity in either male.

\section{Among-host variation}

Of the 41 ETs recovered from the people, two $(5 \%)$ were shared between individuals, one (ET 15) between the female of household 1 and the male of household 2, whilst the other (ET 16) was shared between the members of household 2. A nested analysis (male versus female nested within household) showed that household explained none of the observed allelic variation (AMOVA: $p>0.77)$, whilst variation among individuals of the same household accounted for, on average, $29 \%$ (AMOVA: $p<0 \cdot 001$ ) of the allelic diversity.

\section{Growth characteristics of the ETs}

The growth rate-temperature relationship of an example of every ET recovered from each of the six populations was determined (Table 2). Analysis of these 


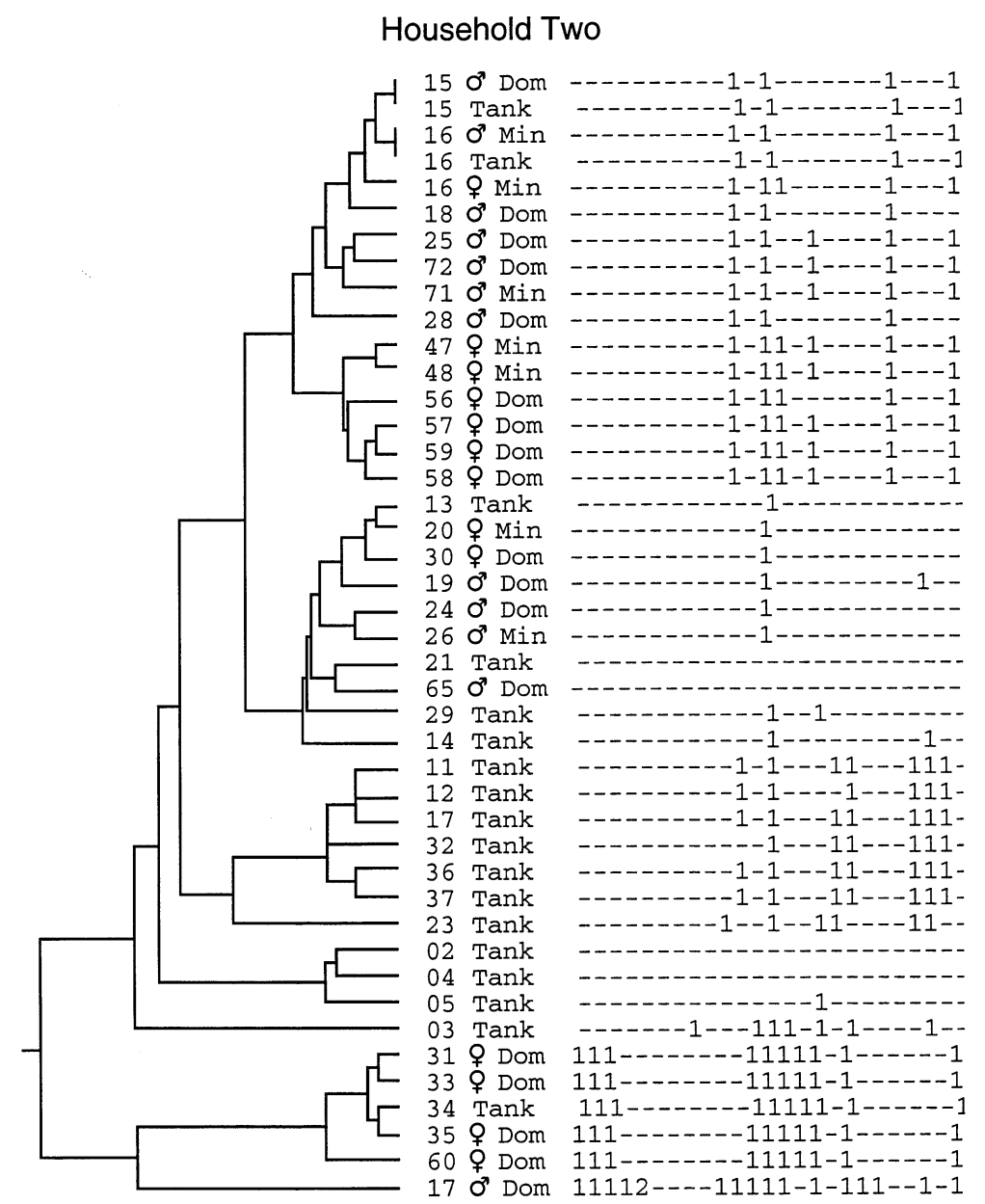

Fig. 2. Genetic similarity among $E$. coli strains isolated from the human members and septic tank of household 2. Details are as for Fig. 1.

Table 2. The growth rate $\left(\mathrm{h}^{-1}\right)$ of $E$. coli strains in LB broth isolated from humans (primary habitat) and septic tanks (secondary habitat) at different temperatures

\begin{tabular}{|c|c|c|c|c|}
\hline \multirow[t]{2}{*}{ Temperature $\left({ }^{\circ} \mathrm{C}\right)$} & \multicolumn{2}{|c|}{$\begin{array}{l}\text { Household } 1 \text { growth rate }\left(h^{-1}\right) \\
\qquad(\text { mean } \pm \text { SEM })\end{array}$} & \multicolumn{2}{|c|}{$\begin{array}{c}\text { Household } 2 \text { growth rate }\left(h^{-1}\right) \\
(\text { mean } \pm \text { SEM })\end{array}$} \\
\hline & $\begin{array}{l}\text { Primary } \\
(n=18)^{*}\end{array}$ & $\begin{array}{l}\text { Secondary } \\
\quad(n=28)\end{array}$ & $\begin{array}{l}\text { Primary } \\
(n=25)\end{array}$ & $\begin{array}{l}\text { Secondary } \\
\quad(n=18)\end{array}$ \\
\hline 12 & $0 \cdot 11 \pm 0 \cdot 008$ & $0 \cdot 11 \pm 0 \cdot 005$ & $0 \cdot 13 \pm 0 \cdot 008$ & $0 \cdot 15 \pm 0 \cdot 011$ \\
\hline 14 & $0 \cdot 13 \pm 0 \cdot 013$ & $0 \cdot 13 \pm 0 \cdot 009$ & $0 \cdot 15 \pm 0 \cdot 011$ & $0 \cdot 17 \pm 0 \cdot 012$ \\
\hline $17 \cdot 5$ & $0 \cdot 19 \pm 0 \cdot 005$ & $0 \cdot 18 \pm 0 \cdot 002$ & $0 \cdot 19 \pm 0 \cdot 003$ & $0 \cdot 20 \pm 0 \cdot 007$ \\
\hline 19 & $0 \cdot 22 \pm 0 \cdot 003$ & $0 \cdot 21 \pm 0 \cdot 003$ & $0 \cdot 21 \pm 0 \cdot 003$ & $0 \cdot 23 \pm 0 \cdot 007$ \\
\hline 25 & $0 \cdot 40 \pm 0 \cdot 006$ & $0 \cdot 40 \pm 0 \cdot 004$ & $0 \cdot 41 \pm 0 \cdot 006$ & $0.43 \pm 0.008$ \\
\hline $26 \cdot 5$ & $0 \cdot 44 \pm 0.006$ & $0 \cdot 45 \pm 0 \cdot 005$ & $0 \cdot 44 \pm 0 \cdot 006$ & $0 \cdot 44 \pm 0 \cdot 009$ \\
\hline 29 & $0 \cdot 54 \pm 0 \cdot 007$ & $0.55 \pm 0.006$ & $0.55 \pm 0.005$ & $0.55 \pm 0.008$ \\
\hline 32 & $0 \cdot 65 \pm 0 \cdot 010$ & $0 \cdot 67 \pm 0.005$ & $0 \cdot 66 \pm 0 \cdot 004$ & $0.65 \pm 0.008$ \\
\hline 34 & $0 \cdot 72 \pm 0 \cdot 008$ & $0 \cdot 72 \pm 0.004$ & $0 \cdot 73 \pm 0.005$ & $0 \cdot 71 \pm 0 \cdot 011$ \\
\hline 37 & $0 \cdot 87 \pm 0 \cdot 015$ & $0 \cdot 88 \pm 0 \cdot 010$ & $0 \cdot 89 \pm 0 \cdot 008$ & $0 \cdot 87 \pm 0 \cdot 023$ \\
\hline 39 & $0 \cdot 97 \pm 0 \cdot 014$ & $0 \cdot 96 \pm 0 \cdot 010$ & $0 \cdot 97 \pm 0 \cdot 010$ & $0 \cdot 93 \pm 0 \cdot 027$ \\
\hline 41 & $1 \cdot 00 \pm 0 \cdot 010$ & $1 \cdot 00 \pm 0 \cdot 009$ & $1 \cdot 02 \pm 0 \cdot 009$ & $0.96 \pm 0.033$ \\
\hline 44 & $0.70 \pm 0.035$ & $0 \cdot 73 \pm 0.021$ & $0.73 \pm 0.024$ & $0.59 \pm 0.071$ \\
\hline
\end{tabular}

* No. strains examined per population. One strain representing every ET from each of the six populations was selected (Table 1). 
Table 3. Analysis of variance examining the factors influencing the growth rate in LB broth of $E$. coli strains isolated from the human members and septic tanks of two households

\begin{tabular}{|c|c|c|c|c|c|}
\hline \multirow[t]{2}{*}{ Source of variation } & \multirow[t]{2}{*}{ d.f. } & \multicolumn{2}{|c|}{ Household 1} & \multicolumn{2}{|c|}{ Household 2} \\
\hline & & $F$ ratio & $P>F$ & $F$ ratio & $\boldsymbol{P}>\boldsymbol{F}$ \\
\hline Habitats & 1 & $0 \cdot 51$ & $0 \cdot 476$ & 3.76 & $0 \cdot 053$ \\
\hline Temperature & 12 & $1841 \cdot 51$ & $<0 \cdot 001$ & $677 \cdot 71$ & $<0.001$ \\
\hline Habitats/temperature & 12 & $0 \cdot 70$ & $0 \cdot 755$ & $4 \cdot 05$ & $<0.001$ \\
\hline PCO-1 $(39 \%, 28 \%)^{*}$ & 1 & $0 \cdot 04$ & $0 \cdot 845$ & $2 \cdot 97$ & 0.085 \\
\hline PCO-2 (17\%, $19 \%)$ & 1 & 3.08 & $0 \cdot 079$ & $0 \cdot 008$ & $0 \cdot 929$ \\
\hline PCO-3 $(13 \%, 15 \%)$ & 1 & $34 \cdot 24$ & $<0 \cdot 001$ & $32 \cdot 64$ & $<0.001$ \\
\hline PCO-4 $(7 \%, 6 \%)$ & 1 & $4 \cdot 00$ & $0 \cdot 046$ & $2 \cdot 18$ & $0 \cdot 140$ \\
\hline
\end{tabular}

*Proportion of the among-strain variation in genetic distance explained by each principal coordinates axis (PCO) (household 1, household 2, respectively).

data revealed that, as was the case for the genetic data, the results of the growth rate analyses differed between households.

In household 1, no difference in the growth characteristics of the strains from the primary and secondary populations was detected (Table 2). Temperature explained most of the variation in the observed growth rates (Temperature; Table 3). Overall, the growth rate of strains isolated from the primary and secondary environments did not differ (Habitats; Table 3). Nor did the manner in which the growth rate changed with temperature vary between strains isolated from the two habitats (Habitats/Temperature interaction; Table 3).

By contrast, in household 2 the growth rate-temperature relations of strains from the primary and secondary populations were found to differ. The significant Habitat/Temperature interaction term indicates that strains from the two environments responded differently to changes in temperature (Table 3). On average, at low temperatures $\left(<26.5^{\circ} \mathrm{C}\right)$ strains from the septic tank consistently had higher growth rates than strains from the primary habitats, whilst at high temperatures $\left(>32^{\circ} \mathrm{C}\right.$ ) strains from the septic tank grew more slowly than did strains from the humans (Table 2).

For both households, genetically similar strains tended to have similar growth characteristics as indicated by the result that PCO-3 and PCO-4 (household 1) and PCO-3 (household 2) explained a significant amount of the growth rate variation among strains. However, the effects were small and, adjusting for the fact that genetically similar strains had similar growth characteristics, had no effect on the outcome of the analyses.

\section{Population dynamics of $E$. coli in the septic tanks}

At the simplest level, the dynamics of cell density ( $n$ cells $\mathrm{ml}^{-1}$ ) in the septic tanks are governed by the immigration of cells into the tank $\left(\lambda\right.$ cells $\left.\mathrm{ml}^{-1} \mathrm{day}^{-1}\right)$ and the loss of cells due to washout $\left(\mu \mathrm{day}^{-1}\right)$. This assumes that the only cell death that occurs is due to washout. Whilst this assumption is unlikely to be true, it forms a useful starting point for investigating the dynamics. Therefore, the rate of change in cell density is $\mathrm{d} n / \mathrm{d} t=\lambda-\mu n$. This leads to a predicted equilibrium cell density, $n^{*}$, of $n^{*}=\lambda / \mu$.

There are two potential sources of E. coli in the septic tank: from the people living in the household and from the storage tank providing water to the household. Total coliform counts in the water storage tanks were about 100 cells $^{-1}$ and no E. coli were recovered. Thus, the only significant inputs to the septic tanks were from the household members. The immigration rate of cells into the septic tank is a function of the number of grams of faeces produced per person per day and the number of cells per gram faeces. It has been estimated that an adult human, male or female, produces about $100 \mathrm{~g}$ faecal material per day (Cummings et al., 1992). The cell densities estimated in this study averaged $4.5 \times 10^{7}$ cells $\mathrm{g}^{-1}$ and ranged from $10^{7}$ to $10^{8}$, values well within those previously reported (Hartl \& Dykhuizen, 1984). Given that two people are providing inputs to the septic tank, and that the volume of the septic tank is 9001 , this results in a mean $\lambda$ of $1 \times 10^{4}$ cells $\mathrm{ml}^{-1} \mathrm{day}^{-1}$. The flow rates into the septic tanks range from 10 to $20 \mathrm{l} \mathrm{day}^{-1}$ and the septic tanks had a volume of 9001 . This results in turnover rates of between 0.011 and $0.022 \mathrm{day}^{-1}$. Given the estimated values for $\mu$ and $\lambda$, then the equilibrium density of cells in the septic tank would be predicted to be $4.5 \times 10^{5}$ to $9 \cdot 0 \times 10^{5}$ cells ml $^{-1}$, depending on whether the maximum or minimum estimates of flow rate are used. Observed cell densities in the septic tank averaged $1.4 \times 10^{4}$ cells ml $^{-1}$, about 10 - to 100 -fold lower than predicted if the cells were simply being washed out of the septic tanks. Even if, on average, only one person was providing inputs to the septic tank, the discrepancy between observed and predicted equilibrium cell densities would still be substantial. This result indicates that cells are not simply being washed out of the septic tanks but that the population growth rate of cells in the septic tank is $<0$, that is, cells are dying. Given that estimates are available for $n^{*}$ and $\lambda$, it is 
possible to estimate $\mu$. Solving for $\mu$ results in an estimated cell death rate between 0.36 and $0.72 \mathrm{day}^{-1}$ or mean cell life spans of 1.5-2.8 days, depending on whether one or two people are providing inputs.

\section{DISCUSSION}

\section{Variation within and among hosts}

About $25 \%$ of the within-host variation in clonal diversity was due to temporal variation and this value is comparable to previously reported estimates (Whittam, 1989). On average, temporal variation explained less of the ET diversity observed in the septic tanks.

Selective plating for strains occurring at low frequencies accounted for over one-third of the ETs recovered from the humans. In the two female hosts, the minority strains represented populations that were genetically distinct from the dominant strains recovered from those hosts. Other studies have demonstrated the presence of low-frequency strains in hosts that are genetically distinct from the numerically dominant strains (Johnson et al., 1998, 2001b). Further studies are required in order to determine if these 'minority' strains typically occur at low frequencies or fluctuate in abundance to the extent that they can sometimes be detected without the use of selective plating.

Overall, differences among individuals accounted for $29 \%$ of the observed allelic diversity within a household. Between-household differences accounted for none of the observed diversity. Thus, the E. coli of individuals living in the same household are no more genetically similar than those of people living in different households. Caugant et al. (1984) observed a similarly low degree of among-household differentiation (6\%), although they sampled families living in different cities.

Gordon (2001) suggests that most of the amongpopulation differentiation observed in E. coli occurs at the level of the individual host and little geographical differentiation is apparent among E. coli populations. The results of this study provide additional support for these conclusions.

\section{Transition between primary and secondary environments}

The consequences of the movement of E. coli cells from the gastrointestinal environment to the septic tank environment differed substantially between households. In household 1, the transition resulted in a small but significant increase in ET diversity, although it explained none of the allelic diversity observed in household 1. Thus, the E. coli from the septic tank of this household did not represent a population of strains genetically distinct from the E. coli recovered from the household members.

By contrast, in household 2 there was a substantial and statistically significant decline in ET diversity in the septic tank population compared to the primary populations (Table 1). Further, the strains isolated from the septic tank were, on average, genetically distinct from strains isolated from either of the human hosts. In addition, the growth characteristics of strains recovered from the septic tank were different from those of the strains recovered from the primary habitat.

The reasons for the differences between the households are unknown. The only obvious difference between households was the source of inputs to the septic tank. In household 1 the only inputs were water and human faeces. In household 2 there were also inputs from the kitchen sink.

In household 2 there appear to be 'septic tank' strains, that is strains 'adapted' to the environment of the septic tank. The source of these strains is unknown. For a strain to achieve a density of $1 \times 10^{4}$ cells ml $\mathrm{m}^{-1}$ in the septic tank solely through immigration would require an immigration rate of a least $1.4 \times 10^{8}$ cells day ${ }^{-1}$. This is a minimum estimate, as it assumes no cell death except that due to washout. Further, to achieve the observed septic tank cell densities would have required this level of input for about 2 months prior to the samples being taken. An immigration rate of this magnitude represents the input rate that would be achieved by a strain that occurs at a density of at least $1.4 \times 10^{6}$ cells $\left(\mathrm{g}\right.$ faeces) ${ }^{-1}$. A strain occurring at this frequency should have been detected in the household members using non-selective plating. No E. coli were observed in the tank providing water to this household. Thus, sustained inputs from external sources were unlikely to have accounted for the population densities of these strains. Rather, these 'septic tank' strains must have population rates of change in the septic tank that are greater than most $E$. coli strains isolated from the members of this household. The observed growth characteristics of strains isolated from the septic tank supports this conclusion. Septic tank strains had higher growth rates at low temperatures and lower growth rates at high temperatures compared to strains isolated from household members.

Whittam's (1989) study of E. coli isolated from domestic birds and the litter on which these birds were raised revealed that, on average, E. coli strains isolated from the birds were genetically distinct from strains isolated from the litter. In the present study, the results for household 2 are similar to those reported by Whittam (1989) in that a significant degree of population differentiation was detected between strains isolated from the septic tank habitat and those isolated from the household members. This observation supports the suggestion of Whittam (1989) that selection, rather than changes in the physiology of individual cells, may be the dominant force in determining the outcome of the transition between primary and secondary environments, although the physiological mechanisms suggested by Savageau (1983) undoubtedly have a role in extending the survival capabilities of $E$. coli cells in the external environment.

The household/septic tank system used in this study 
seems to be an excellent model with which to pursue questions related to the fate of E. coli during the transition from primary habitats to the external environment. The septic tank represents a discrete environment where the inputs to the system are unambiguous. Furthermore, such systems are simple, essentially closed and intimately associated physically. Most other systems, for example runoff from a pasture into a river, are more complex. If, on average, the clonal composition of populations in household members is different from the septic tank population, then it is likely that the same outcome will be observed in more complex systems.

The results of the present study suggest ways in which the sampling design used in this study could be modified. First, a crude determination of the E. coli cell density in a septic tank is required, in addition to knowledge of the volume of the tank and an estimate of the flow rate into the septic tank. These data permit the magnitude of the input required to achieve the observed cell density to be estimated. Such an estimate would give an indication of how intensely the primary population needs to be sampled in order to detect a strain that is abundant in the septic tank. Flow rates will vary with the number of household members and with the number of inputs (showers, sinks, etc.) to the septic tank. Higher flow rates require higher input rates in order to achieve a given cell density in the septic tank. These considerations suggest that only clones recovered through non-selective plating need be considered. A similar number of isolates from each septic tank should be examined. The analysis of septic tank dynamics also suggests that consequences of inputs due to short-term guests in a household can be ignored. Unless cells from such sources are 'adapted' to the septic tank environment, they will never achieve significant densities. Temporal variation accounts for a significant fraction $(25 \%)$ of the ET diversity observed in a human host. Consequently, multiple samples should be taken per host and the samples should be taken at 2- to 4-day intervals. On average, temporal effects accounted for less of the observed ET diversity in the septic tanks $(7 \%)$, which suggests that fewer samples would need to be taken from the septic tank.

In this study, two different outcomes resulted from the transition of E. coli from the host habitat to the septic tank environment. The outcome for household 1 would suggest that one of the assumptions underlying attempts to trace the source of coliform contamination in the environment is validated. That is, the clonal composition of E. coli populations in secondary environment reflects the clonal composition in the host population. By contrast, the outcome for household 2 invalidates this assumption. Further, the results for household 2 suggest that absolute numbers of coliforms present in the environment may be a very poor indicator of the degree of faecal contamination. The dichotomy in the results for the two households examined in the present study highlights the need for further investigations concerning the fate of $E$. coli cells during the transition from the host environment to the external environment.

\section{ACKNOWLEDGEMENTS}

The Australian Research Council supports David Gordon's research. James Johnson's research is supported by Office of Research and Development, Medical Research Service, Department of Veterans Affairs, National Institutes of Health grant DK-47504, and National Research Initiative (NRI) Competitive Grants Program/United States Department of Agriculture grant 00-35212-9408. Adam L. Stell provided expert technical assistance.

\section{REFERENCES}

Caugant, D. A., Levin, B. R. \& Selander, R. K. (1984). Distribution of multilocus genotypes of Escherichia coli within and between host families. J Hyg 92, 377-384.

Cummings, J. H., Bingham, S. A., Heaton, K. W. \& Eastwood, M. A. (1992). Faecal weight, colon cancer risk, and dietary intake of nonstarch polysaccharides (dietary fibre). Gastroenterology 103, 1783-1789.

Dombek, P. E., Johnson, L. K., Zimmerley, S. T. \& Sadowsky, M. J. (2000). Use of repetitive DNA sequences and the PCR to differentiate Escherichia coli isolates from human and animal sources. Appl Environ Microbiol 66, 2572-2577.

Espinosa-Urgel, M. \& Kolter, R. (1998). Escherichia coli genes expressed preferentially in an aquatic environment. Mol Microbiol 28, 325-332.

Excoffier, L., Smouse, P. E. \& Quattro, J. M. (1992). Analysis of molecular variance inferred from metric distances among DNA haplotypes: application to human mitochondrial DNA restriction data. Genetics 131, 479-491.

Gordon, D. M. (2001). Geographical structure and host specificity in bacteria and the implications for tracing the source of coliform contamination. Microbiology 147, 1079-1085.

Gordon, D. M. \& Lee, J. (1999). The genetic structure of enteric bacteria from Australian mammals. Microbiology 145, 26732682.

Hartl, D. L. \& Dykhuizen, D. E. (1984). The population genetics of Escherichia coli. Annu Rev Genet 18, 31-68.

Johnson, J. R. (1991). Virulence factors in Escherichia coli. Clin Microbiol Rev 4, 80-128.

Johnson, J. R. \& Stell, A. L. (2000). Extended virulence genotypes of Escherichia coli strains from patients with urosepsis in relation to phylogeny and host compromise. J Infect Dis 181, 261-272.

Johnson, J. R., Brown, J. J., Carlino, U. B. \& Russo, T. A. (1998). Colonization with and acquisition of uropathogenic Escherichia coli as revealed by polymerase chain reaction-based detection. J Infect Dis 177, 1120-1124.

Johnson, J. R., Delavari, P., Kuskowski, M. \& Stell, A. L. (2001a). Phylogenetic distribution of extraintestinal virulence-associated traits in Escherichia coli. J Infect Dis 183, 78-88.

Johnson, J. R., Stell, A. L., Delavari, P., Murray, A. C., Kuskowski, M. \& Gaastra, W. (2001b). Phylogenetic and pathotypic similarities between Escherichia coli isolates from urinary tract infections in dogs and extraintestinal infections in humans. J Infect Dis 183, 897-906.

Leclerc, H., Mossel, D. A. A., Edberg, S. C. \& Struijk, C. B. (2001). Advances in the bacteriology of the coliform group: their suitability as markers of microbial safety. Annu Rev Microbiol 55, 201-234.

Nei, M. (1978). Estimation of average heterozygosity and genetic distance from a small number of individuals. Genetics 89, $583-590$. 
Okada, S. \& Gordon, D. M. (2001). Host and geographical factors influence the thermal niche of enteric bacteria isolated from native Australian mammals. Mol Ecol 10, 2499-2513.

Parveen, S., Murphree, R. L., Edminston, L., Kasper, C. W., Portier, K. M. \& Tamplin, M. L. (1997). Association of multiple-antibiotic resistance profiles with point and nonpoint sources of Escherichia coli in Apalachicola Bay. Appl Environ Microbiol 63, 2607-2612.

Parveen, S., Portier, K. M., Robinson, K., Edmiston, L. \& Tamplin, M. L. (1999). Discriminant analysis of ribotype profiles of Escherichia coli for differentiating human and nonhuman sources of fecal pollution. Appl Environ Microbiol 65, 3142-3147.

Power, D. A. \& McCuen, P. L. (1988). Manual of BBL Products and Laboratory Procedures, 6th edn. Cockeysville, MD: Becton Dickinson Microbial Systems.
Pupo, G. M. \& Richardson, B. J. (1995). Biochemical genetics of a natural population of Escherichia coli: seasonal changes in alleles and haplotypes. Microbiology 141, 1037-1044.

Savageau, M. A. (1983). Escherichia coli habitats, cell types, and molecular mechanisms of gene control. Am Nat 122, 732-744.

Siitonen, A. (1994). What makes Escherichia coli pathogenic. Ann Med 4, 229-231.

Whittam, T. S. (1989). Clonal dynamics of Escherichia coli in its natural habitat. Antonie Leeuwenhoek 55, 23-32.

Wright, S. (1943). Isolation by distance. Genetics 28, 114-138.

Received 11 June 2001; revised 11 January 2002; accepted 16 January 2002. 